\title{
Effects of CdSe/ZnS quantum dots covered multi-walled carbon nanotubes on murine embryonicstem cells
}

Daxiang Cui ${ }^{1,2, *}$, Hong Zhang $^{2}$, Jie Sheng ${ }^{3}$, Zheng Wang ${ }^{3}$, Asahi Toru ${ }^{2}$, Rong $\mathrm{He}^{1}$, Osaka Tetsuya ${ }^{2}$, Feng Gao ${ }^{1}$, Hoon Sung Cho ${ }^{4}$, Chris $\mathrm{Huth}^{4}, \mathrm{Hengya}$ $\mathrm{Hu}^{1}$, Giovanni M. Pauletti ${ }^{5}$ and Donglu Shi ${ }^{1,4}$

\begin{abstract}
${ }^{1}$ Department of Bio-Nano-Science and Engineering, National Key Laboratory of Nano/Micro Fabrication Technology, Key Laboratory for Thin Film and Microfabrication of Ministry of Education, Institute of Micro-Nano Science and Technology, Shanghai JiaoTong University, 800 Dongchuan Road, Shanghai 200240, China

${ }^{2}$ Consolidated Research Institute for Advanced Science and Medical Care, Waseda University, 513 Wasedatsurumaki-cho, Shinjuku-ku, Tokyo 1620041, Japan

${ }^{3}$ Stem Cell Lab., Institute of Digestion Diseases, RenJi Hospital, Shanghai JiaoTong University, Shandong Road, Shanghai20001, China

${ }^{4}$ Department of Chemical and Materials Engineering, University of Cincinnati, Cincinnati, OH 45221, USA

${ }^{5}$ James L. Winkle College of Pharmacy, University of Cincinnati, Cincinnati, OH 45267, USA

*Corresponding author: dxcui@sjtu.edu.cn or daxiangcui@aoni.waseda.jp
\end{abstract}

\begin{abstract}
Stem cells nanotechnology has emerged as a new exciting area, and holds great potential for research and development of stem cells as novel therapeutic platforms for genetic, traumatic, and degenerative medicine. Vital to the success of this technology are approaches that reproducibly facilitate in vivo cell tracking, expansion, differentiation, and transplantation. Herein we reported the effects of CdSe/ZnS quantum dots covered multi-walled carbon nanotubes (FMNTs) on mice embryonic stem cell line CCE cells. The FMNTs were prepared by plasma surface treatment and characterized by high resolution transmission electron microscopy (HR-TEM), and incubated with murine ES CCE cells for 1 to 28 day.These ES cells were observed by confocal laser scanning microscopy, and were analyzed by real time reverse transcription-polymerase chain reaction (RTPCR), flow cytometry (FCM) and MTT method. Results showed that prepared FMNTs exhibited green fluorescent signal, could enter into ES cells in time-dependent means, more than $20 \mu \mathrm{g} \mathrm{ml}^{-1}$ FMNTs induced ES cells become smaller and smaller as the incubation time increased, and inhibited

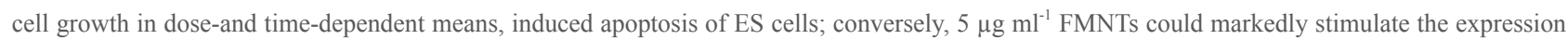
of Sox1 and Hsp27, and inhibit expression of OCT4 in ES cells, FCM analysis showed that differentiation marker Flk-1 exhibited higher expression compared with control ES cells. In conclusion, high dose of FMNTs can inhibit proliferation of ES cells, low dose of FMNTs can improve the differentiation of ES cells, FMNTs can have potential applications in in vivo tracking, imaging and regulation of the proliferation and differentiation of ES cells.
\end{abstract}

Key Words: CdSe/ZnS quantum dots, multi-walled carbon nanotubes, murine embryonic stem cells, proliferation, differentiation, apoptosis

Citation: D. Cui, et al. Effects of CdSe/Zs quantum dots covered multi-walled carbon nanotubes on murine embryonic stem cells. Nano Biomed. Eng. 2010, 2(4), 236-244.DOI: 10.5101/nbe.v2i4.p236-244.

\section{1 . Introduction}

Generating progenitor cells with in vivo reconstitution functions has been at the center of intense research to accelerate biomedical applications of embryonic stem cells (ES) for the treatment of debilitating genetic, traumatic, and degenerative diseases [1-3]. A major challenge for clinical development of these pluripotent cells is effective, non-invasive imaging of transplanted cells to monitor biodistribution (i.e., in vivo tracking). Furthermore, reproducible approaches need to be developed enabling efficient intracellular delivery of biomolecules, including
DNA, RNA and proteins, required to control ES cell differentiation. Physical methods such as electroporation and nucleofection offer the advantage of high delivery efficiency but frequently cause severe damage to ES cells [4]. Viral vectors, including retro-, lenti-, and adenoviruses, result in successful transfection and reproducible manipulation of ES differentiation in vitro. However, risk of toxicity, immunogenicity, and increased mutagenesis significantly decrease clinical viability of these viral carriers for biomedical application 
[5,6]. Therefore, non-viral vectors such as polymeric nanoparticles and liposomes are currently pursued as the most promising nanotechnology platform to translate exciting laboratory findings with ES cells into clinically viable applications.

Innovative design of multifunctional nanostructures aims at facilitating reproducible intracellular accumulation of non-viral nanocarriers in ES cells. Material properties and structural features of the carrier define preference for receptor-mediated or non-energy-dependent endocytosis pathways. In both cases, however, endosomal escape and avoidance of lysosomal degradation are required to successfully track and manipulate stem cells. Functionalized carbon nanotubes have emerged as a new category of nanovectors for effective delivery of biomolecules into mammalian cells following recent discovery of their capacity to internalize into cells [7-9]. Furthermore, therapeutic molecules can be effectively loaded inside or outside of carbon nanotubes through formation of stable covalent bonds or supramolecular assemblies based on noncovalent interactions [10-12]. The application of carbon nanotubes in the field of stem cell research, however, has not been significantly explored.

In this study, we developed a unique, multifunctional nanostructure consisting of multi-walled carbon nanotubes with surface-conjugated $\mathrm{CdSe} / \mathrm{ZnS}$ quantum dots (FMNTs), and investigated the effects of as-prepared FMNTs on murine embryonic stem cells with the aim of developing a new method to regulate proliferation and differentiation of ES cells based on nanomaterials. Results showed that high dose of FMNTs can inhibit proliferation of ES cells by time-and dose-dependent means, low dose of FMNTs can improve the growth and differentiation of ES cells, FMNTs have potential applications in in vivo imaging, tracking, and regulation of the proliferation and differentiation of murine ES cells under suitable doze.

\section{Materials and Methods}

\subsection{Materials source}

$\mathrm{CdSe} / \mathrm{ZnS}$ quantum dots (emission wavelength of 600 $\mathrm{nm})$ were purchased from Evident Technologies, NY, commercial grade multi-walled carbon nanotubes(MNTs) were obtained from Applied Science Inc. in USA, murine CCE ES cell line was obtained from StemCell Technologies and maintained according to a protocol. RPMI 1640 medium containing 10\% fetal calf serum was from Gibco Company. MTT(3-(4,5-dimethyl-2-thiazolyl)2,5-diphenyl-2H-tetrazolium bromide) was obtained from Dojin Laboratories (Kumamoto, Japan). PI was obtained from Gene Company. PCR primers were designed and synthesized by Shanghai Bioengineering Company. QPCR kit was from TakaRa Company. Other reagents were from Sigma Company.

\subsection{Fabrication and Characterization of $\mathrm{CdSe} / \mathrm{ZnS}$ QDs covered MNTs}

The multi-walled carbon nanotubes were chosen for their relatively larger inner wall diameters $(50-80 \mathrm{~nm})$, which are more suitable for cargo storage. An ultrathin
( 1-2 $\mathrm{nm}$ ) acrylic acid polymer film was deposited on MNTs by plasma coating to provide carboxyl functional groups for covalent coupling of $\mathrm{CdSe} / \mathrm{ZnS}$ quantum dots. They were functionalized with amine and packed in water at a concentration of $2.6 \mathrm{nmol} \mathrm{mL}^{-1}$ core $\mathrm{CdSe} /$ $\mathrm{ZnS}$ quantum dot. To generate the FMNT heterostructure, a previously published carboxyl/amine coupling protocol was applied using 1-ethyl-3-(3-dimethylaminopropyl) carbodiimide $\mathrm{HCl}$ (EDC) and N-hydroxysuccinimide (sulfo-NHS) in PBS, $\mathrm{pH}=7.4$ [13]. Fabricated FMNTs were characterized by fluorescent spectroscopy and high resolution transmission electronic microscope (HR-TEM) [31].

\subsection{Cell Culture and Proliferation Assay}

Murine CCE ES cells were maintained at $37^{\circ} \mathrm{C}$ in a humidified 5\% $\mathrm{CO}_{2}$ and $95 \%$ air atmosphere using DMEM supplemented with $10 \%(\mathrm{v} / \mathrm{v})$ fetal calf serum, $1 \times 10^{5}$ $\mathrm{mU} \mathrm{mL} \mathrm{m}^{-1}$ of penicillin, $0.1 \mathrm{mg} \mathrm{mL}^{-1}$ of streptomycin, 2 $\mathrm{mmolL}^{-1}$ L-glutamine, $0.1 \mathrm{mmolL}^{-1} \mathrm{MEM}$ nonessential amino acids, and $10 \mathrm{ng} \mathrm{mL^{-1 }}$ leukemia inhibitory factor (Gibco Laboratories). The media was exchanged every other day [14,15]. For uptake and proliferation studies, CCE ES cells were seeded into 24-well plates at a density of 5000 cells/well and maintained under normal culture conditions. $24 \mathrm{~h}$ post-seeding cells were incubated at $37^{\circ} \mathrm{C}$ for maximum 5 days with FMNTs $\left(0-80 \mu \mathrm{gmL}^{-1}\right)$. Proliferation was monitored using the commercial MTT (3-(4,5-dimethyl-2-thiazolyl)-2,5-diphenyl2H-tetrazolium bromide) assay (Dojin Laboratories, Kumamoto, Japan). For differentiation studies, EBs from ES cells treated with $5 \mu \mathrm{g} \mathrm{mL} \mathrm{m}^{-1}$ FMNTs and without treatment were transferred to the new culture dishes with non-sera medium and continue to culture at $37^{\circ} \mathrm{C}$ in a humidified $5 \% \mathrm{CO}_{2}$ and $95 \%$ air atmosphere, the nerve differentiation of EBs from ES cells treated with $5 \mu \mathrm{g}$ $\mathrm{mL}^{-1}$ FMNTs were observed. EBs from ES cells treated with $5 \mu \mathrm{g} \mathrm{mL}^{-1}$ FMNTs and control EBs were identified, dissociated via trypsinization, and 15,000 single cells were evenly suspended in $2.7 \mathrm{~mL}$ of methylcellulose media (M3434; StemCell Technologies). The methylcellulose cultures were maintained for additional 12 days [16].

\subsection{Confocal Laser Scanning Microscopy and Flow Cytometry}

Murine CCE ES cells were cultured for $24 \mathrm{~h}$ in 6-well chambered cover slips and fluorescence images of FMNTs-treated or control ES cells were acquired using a Zeiss LSM 510 connected to an Axiovert inverted microscope (Zeiss, Jena, Oberkochen, Germany). The confocal system consisted of a $5 \mathrm{~mW}$ helium/neon laser $(\mathrm{EX}=633 \mathrm{~nm})$. Emission was recorded using the longpass filter sets RG665 and LP515, respectively. Cells for flow cytometry analysis were detached and stained in FACS buffer $\left(0.5 \%\right.$ BSA, 2 mmolL $^{-1}$ EDTA in $1 \times$ PBS) supplemented with annexin V-FITC or Flk-1 antibody. FCM analysis was carried out on FACS Vantage (Becton Dickinson). The gate M1 was set to include $1 \%$ of control cells exhibiting highest fluorescence within the 
length $240 \mathrm{bp}$

population. Cells were considered Flk-1 positive when contained within the gate M1. For FACS sorting, dead cells were excluded by propidium iodide (PI) staining $(0.5$ $\mu \mathrm{g} \mathrm{mL}{ }^{-1}$; Molecular Probes).

\subsection{Reverse Transcription - Polymerase Chain Reaction (RT-PCR) Analysis}

Total RNA was extracted from EBs using the Total RNA Extraction Kit (Promega Inc., USA). Total RNA was treated with RNase-free DNase I to eliminate any residual genomic DNA. Single-strand cDNA was synthesized with oligo (dT) primer using the SuperScript Preamplification System (Promega Company, USA). PCR amplification conditions were set at 30 cycles of $30 \mathrm{~s}$ of denaturation at $95^{\circ} \mathrm{C}, 1 \mathrm{~min}$ annealing at $65^{\circ} \mathrm{C}$, and 1 minute of extension at $72^{\circ} \mathrm{C}$, final extension at $72^{\circ} \mathrm{C}, 5 \mathrm{~min}$. $\beta$-actin was amplified to verify the presence of RNA in the template and used as loading control. RT-PCR products were separated using a $0.8 \%$ Tris/acetate/EDTA (TAE) agarose gel, and bands were visualized under UV light. Images were captured using the ChemiImager 500 system (Alpha Innotech Corporation, San Leandro, CA). Their RT-PCR primers[17-19] are as follows:

Oct4 : 5'-GGCGTTCGCTTTGGAAAGGTGTTC-3' 5'-CTCGAACCACATCCTTCTCT-3', length $260 \mathrm{bp}$.

$\beta$-actin: 5'-GTGGGCCGCTCTAGGCACCAA-3' 5'-CTCTTTGATGTCACGCACGATTTC-3', length $180 \mathrm{bp}$

Sox1: 5'-TCATGGTGTGGTCCCGCGGA-3' 5'-CCAGCGAGTACTTGTCCTTCT-3',

\section{Hsp27: 5'-ACATTGGGTGTGTTGTGG-3' 5'-GGATCATGACTACCGCAC-3', length $291 \mathrm{bp}$}

\section{3 . Results and Discussion}

\subsection{Characterization of FMNTs}

Figure 1A shows the fluorescent and transmitted bright field image of fabricated FMNTs. The bright emission against the dark background implies effective surface deposition of QDs onto acrylic acid-coated MNTs, prepared FMNTs were water-soluble, and dispersed well. High resolution transmission electron microscopy (HRTEM) images of the FMNTs are presented in Figure 1BD. In Panel B, the dark contrast visible on the tubular MNT structure suggests random distribution of QDs with an average particle size of 5-10 $\mathrm{nm}$ on the MNT wall. The diffuse diffraction arc shown in Figure $1 \mathrm{C}$ is consistent with the diffraction from the graphite layer of the MNT, and the ring patterns can be indexed by structural data of $\mathrm{CdSe} / \mathrm{ZnS}$ QDs. High-resolution TEM images (Figure 1D) confirms that the crystalline $\mathrm{CdSe} / \mathrm{ZnS} \mathrm{QD}$ is deposited on the MNT wall.

\subsection{Observation of FMNTs entrance into ES cells}

Time-dependent intracellular accumulation of FMNTs into murine CCE ES cells was monitored by confocal microscopy. The dose of FMNTs used in these experiments was $20 \mu \mathrm{g} \mathrm{mL}^{-1}$. Figure 2 shows the
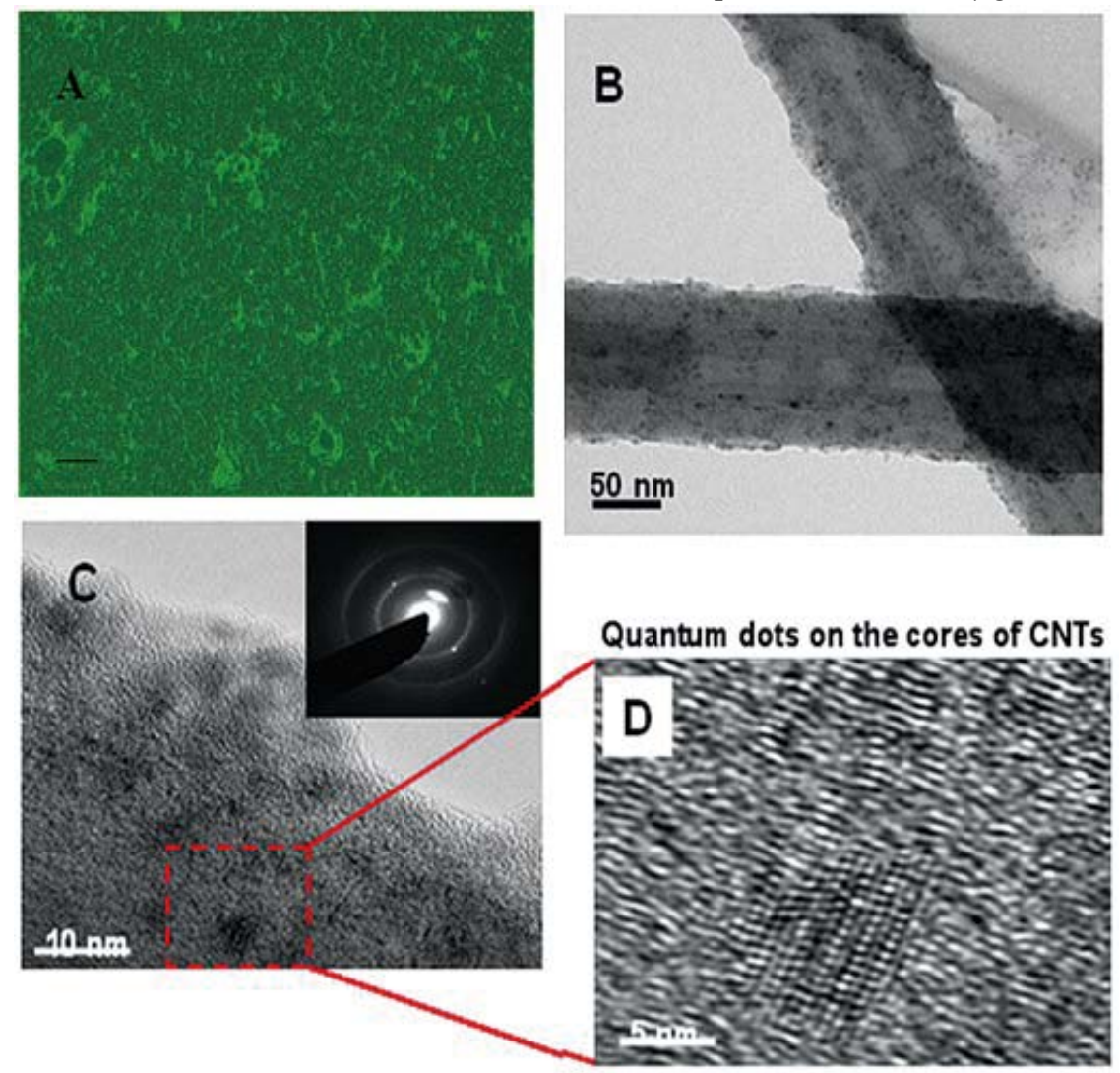

Figure 1 Microscopic characterization of QD-CNTs. Panel A shows a representative fluorescent microscopy image (Olympus $1 X 51$, EX = 350 nm) of fabricated fluorescent CNTs individually labeled with surface-conjugated QDs that exhibit strong emission against the dark background. Panel B depicts a TEM image of CNTs with surface-coupled QDs. Panels C \& D show representative HRTEM images of the crystalline CdSe/ZnS QDs deposited on the CNTs. The inset in Panel C visualizes the selected area electron diffraction pattern acquired from surface-functionalized CNTs. 
results from one representative experiment following microscopic selection of a random ES cell. Panel B visualizes the temporal aspects of this uptake process as a series of consecutive images $(\mathrm{a}-\mathrm{h})$ taken over 180 min from the same cell. A diffuse, bright fluorescence attributed to internalized FMNTs significantly increases over this short time period. Quantitative assessment shown in Panel $\mathrm{C}$ demonstrates a nearly linear increase in fluorescence intensity within the first $60 \mathrm{~min}$, followed by a slower uptake rate that may represent the beginning of intracellular saturation. Similar experiments performed with three other randomly selected CCE ES cells confirmed these findings (data not shown). These results highly suggest that the novel nanocomposite fabricated in this study allows high quantum yield labeling of ES cells that may facilitate effective, non-invasive cell tracking in vivo.

\subsection{MTT analysis of murine CCE ES cells incubated with FMNTs}

Figure 3 shows the results relevant to the effects of fabricated FMNTs on proliferation and viability of murine CCE ES cells. Panel A demonstrates that mitochondrial dehydrogenase activity of this mouse ES cell line is significantly compromised following exposure to FMNTs doses $>20 \mu \mathrm{g} \mathrm{mL}^{-1}$. The data further support a dose- and time-dependent decrease in proliferation rate suggesting reduction in cell viability. Longer incubation periods dramatically increase cytotoxicity of FMNTs. The estimated dose required to reduce cell proliferation by $50 \%$ decreases from $80 \mu \mathrm{g} \mathrm{mL}^{-1}$ at 3 days to $60 \mu \mathrm{g}$ $\mathrm{mL}^{-1}$ at 4 days, and $40 \mu \mathrm{g} \mathrm{mL} \mathrm{m}^{-1}$ at 5 days, respectively. To quantify induction of cell apoptosis, CCE ES cells exposed for 5 days to $5 \mu \mathrm{g} \mathrm{mL}^{-1}$ and $80 \mu \mathrm{g} \mathrm{mL} \mathrm{m}^{-1}$ of FMNTs, respectively, were labeled with 7-aminoactinomycin D (7-AAD) and FITC-conjugated annexin V. The results from fluorescence-activated cell sorter (FACS) analysis shown in Figure 3B \& $\mathrm{C}$ demonstrate that higher doses of these FMNTs significantly increase the fraction of non-viable cells (7-AAD staining) and cells undergoing early stage apoptosis (annexin V staining). Based on these data, future studies were limited to a FMNTs dose of $5 \mu \mathrm{g} \mathrm{mL}^{-1}$, which was considered nontoxic for the selected CCE ES cell line.

\subsection{Effects of FMNTs on differentiation of ES cells}

During normal embryogenesis, ES cells differentiate into the complex three-dimensional structure of embryoid bodies (EB). Strategies to reproducibly induce differentiation of ES cells into EBs are critical to successful clinical development of cell-based therapeutics as cell expansion in bioreactors can be controlled. To assess the impact of FMNTs on this vital cell biology process, a 7 day comparative reverse transcriptasemediated polymerase chain reaction (RT-PCR) profile of three selected marker genes for ES cell differentiation was established in the presence and absence of $5 \mu \mathrm{g}$ $\mathrm{mL}^{-1}$ of FMNTs. Figure 4 shows the results from this semiquantitative study. Under standard culture conditions, EBs from CCE ES cells were formed after 2 days (data not shown). FMNTs suppress expression of Oct-4 transcription factor gene, a prototypic marker of the undifferentiated ES cell phenotype. In contrast to vehicle-treated control cells, where Oct-4 PCR products are detectable until day 5, exposure to FMNTs appears to accelerate the switch to differentiation by two days.

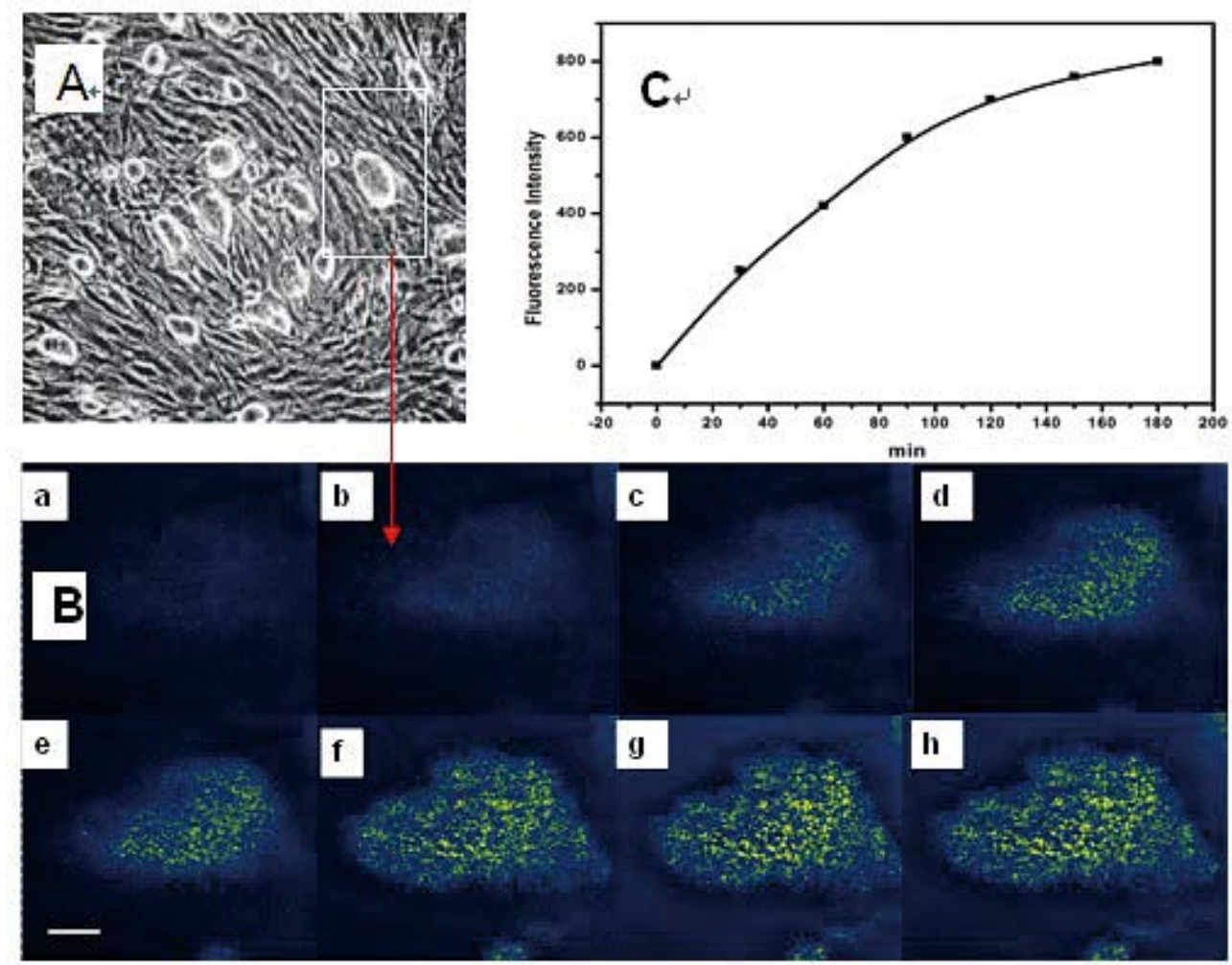

Figure 2 Intracellular accumulation of FMNTs in murine CCE embryonic stem cells. One cell was randomly selected and monitored by confocal microscopy over $180 \mathrm{~min}$ following incubation with $20 \mu \mathrm{g} \mathrm{mL} \mathrm{m}^{-1}$ of FMNTs (Panel B, a-h). Time-dependent cumulative fluorescence intensity attributed to internalized FMNTs is summarized in Panel C. 
A
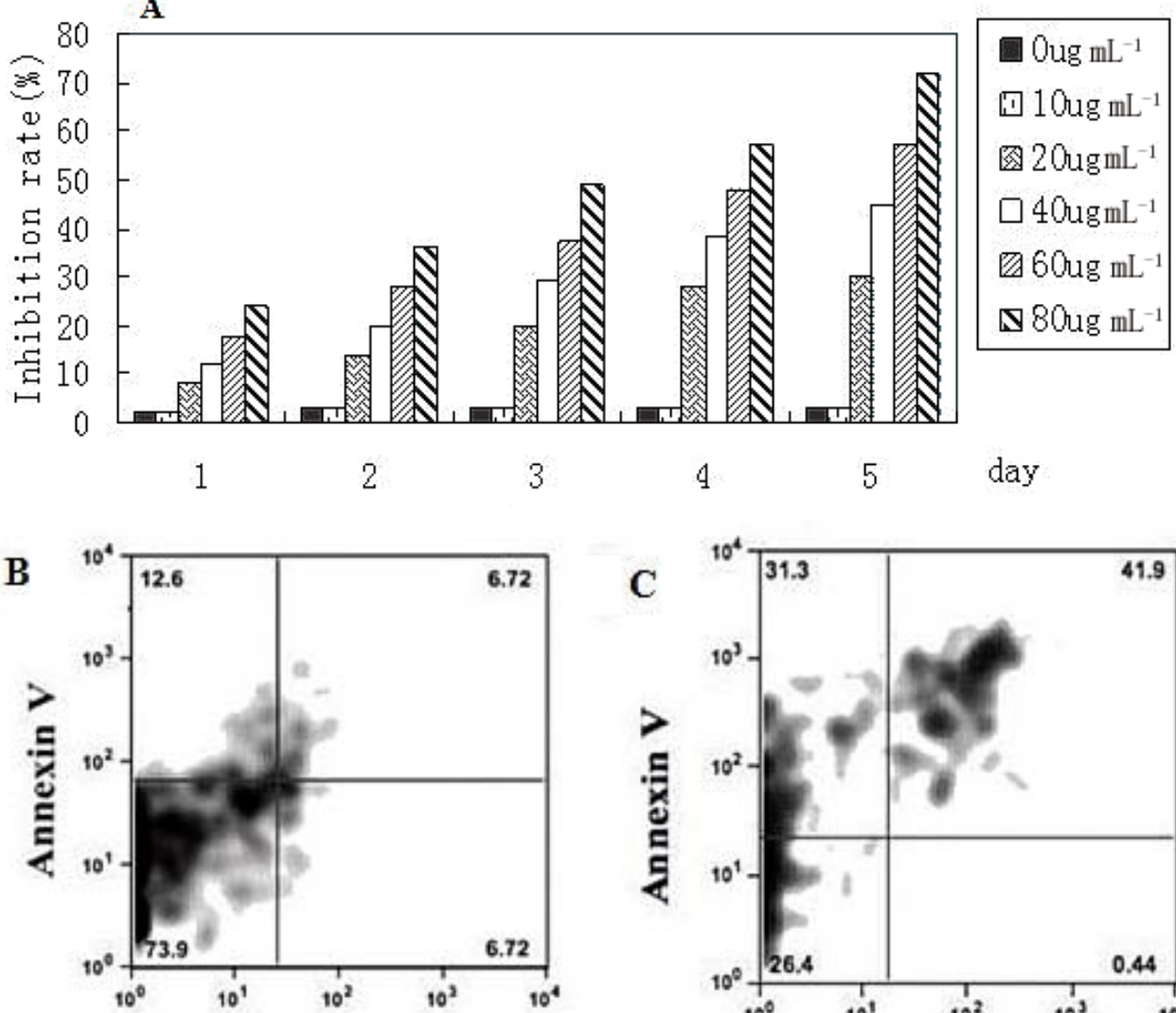

7AAD

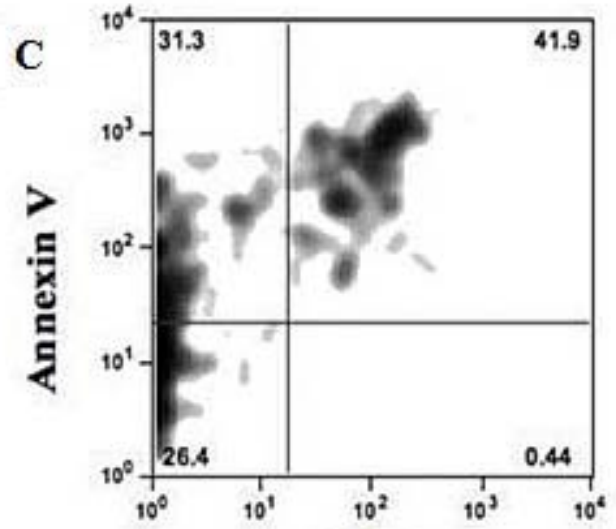

7AAD

Figure 3 Effects of FMNTs on murine CCE ES cells. Cell proliferation rate of CEE ES cells was monitored for 5 days using the MTT assay following incubation with $0-80 \mu \mathrm{g} \mathrm{mL}^{-1}$ of FMNTs (Panel A). Apoptosis induced after a 5 day exposure to $5 \mu \mathrm{g} \mathrm{mL}{ }^{-1}$ (Panel B) or $80 \mu \mathrm{g} \mathrm{mL}{ }^{-1}$ (Panel C) of FMNTs was measured by annexin $\mathrm{V}$ labeling using flow cyotometry.

Simultaneously, cells incubated with FMNTs showed early up-regulation of the differentiation marker genes Sox 1 and Hsp27. These results highly imply that exposure of CCE ES cells to low dose FMNTs, which did not compromise proliferation and cell viability, stimulates differentiation of this murine stem cell line.

In order to further confirm this point, we transfer the EBs from ES cells treated with $5 \mu \mathrm{g} \mathrm{mL}^{-1}$ FMNTs and without treatment to the new culture dishes with nonsera medium, as shown in Figure 5, we observed that EBs from ES cells treated with $5 \mu \mathrm{g} \mathrm{mL}^{-1}$ FMNTs were gradually differentiated into nerve cells within 7 days under the non-sera medium, conversely, the control ES cells were differentiated very slowly. We also transfer the EBs from ES cells treated with $5 \mu \mathrm{g} \mathrm{mL} \mathrm{L}^{-1}$ FMNTs and without treatment to the methylcellulose surface, as shown in Figure 5, compared with the control, EBs from the ES cells treated with $5 \mu \mathrm{g} \mathrm{mL}^{-1}$ FMNTs show early morphological characteristics of hematopoietic differentiation. FCM analysis quantifying the expression of Flk-1, a molecular marker of early hematopoietic precursors such as hemangioblasts, provided further molecular evidence of enhanced differentiation of ES cells when exposed to FMNTs, as shown in Figure 7. Combined, these results support the conclusion that low doses of FMNTs promote nerve or hematopoietic differentiation of CCE SE cells.

\subsection{Potential mechanism}

This is the first report demonstrating enhanced differentiation of ES cells following successful intracellular accumulation of low doses of FMNTs. Endocytosis is generally recognized as the primary pathway for nanovectors to overcome the cell membrane barrier. Kam et al. reported that single-walled carbon nanotubes (SWCNTs) with various surface functionalizations enter living cells predominantly via energy-dependent endocytosis [11]. In most cases, this transfer process involves clathrin-coated pits rather than caveolae or lipid rafts. In contrast, Pantorotto et al. hypothesized that the nanotube uptake by living cells can also occur via an energy-independent nanoendocytosis pathway that involves insertion and diffusion of nanotubes across cell membranes [20,21]. Stem cells membranes, however, exhibit a significantly different glycoprotein composition than more mature hematopoietic cells [32]. Consequently, internalization mechanisms underlying cellular accumulation of FMNTs in CCE ES cells may differ from those established in tumor cells. Preliminary experiments comparing FMNTs uptake in trypsin-treated and untreated CCE ES cells support this hypothesis as enzymatic removal of the glycoprotein layer dramatically increased intracellular accumulation of these unique nanocomposite (data not shown). These results support an energy-independent, nano-endocytotic pathway as originally proposed by Pantorotto and co-workers [20,21] and recently confirmed by Kostarelos, et al. [31]. However, our findings are 
also consistent with the nanosyringe model introduced by Lopez et al. [24]. Delineating the mechanisms by which these multifunctional FMNTs enter ES cells and characterizing details of intracellular trafficking will be subject of further investigations.

The results from our experiments defined a threshold dose of $10 \mu \mathrm{g} \mathrm{mL}^{-1}$ above which FMNTs significantly inhibited proliferation of stem cells in dose- and timedependent manner. At the maximum dose tested, this novel nanocomposite reduced ES cell viability by $70 \%$, with a significant fraction of the cells demonstrating molecular evidence of apoptosis. Previously, SWCNTinduced cytotoxicity and apoptosis of HEK293 cells was concluded to result from binding of these nanomaterials to ion channels and cell surface receptors [25]. The authors hypothesized that this event may negatively affect conformation and function of membrane proteins, thus activating cell signaling pathways that enhance apoptosis. Alternatively, internalized FMNTs may stimulate cell metabolism enzymes associated with endosomal/lysosomal degradation pathways. Formation of free radicals increases oxidative stress leading to structural modifications of vital cellular components, including DNA, RNA, and proteins, that ultimately induce necrosis and cell apoptosis [26-29].
Interestingly, exposure of CCE ES cells to $5 \mu \mathrm{g} \mathrm{mL^{-1 }}$ of FMNTs increased expression of molecular markers associated with differentiation and enhanced formation of secondary EBs upon dissociation in methylcellulosecontaining differentiation media. The balance between proliferation and differentiation of hematopoietic stem cells is critical to ensure long-term hematopoiesis throughout the lifetime of an individual. Disruption of this balance may result in hematopoietic insufficiency associated with diseases such as anemia and blood malignancies. However, controlled regulation of ES cell differentiation also represents a powerful therapeutic tool to correct some of the pathophysiological conditions resulting from imbalanced hematopoiesis. Considering oxidative stress as a dominant mechanism underlying the experimentally observed ES cell cytotoxicity after exposure and internalization of high doses of FMNTs, we could speculate that low doses of FMNTs generate a few reactive oxygen species acting as regulators of cell differentiation. Molecular evidence for such a hypothesis was recently reported by Spike and Macleod [27-32], who identified the $\mathrm{pRb}$ tumor suppressor pathway as a critical cell cycle regulator of hematopoietic hemostasis at the G2/M checkpoint under oxidative stress. Future studies are required to define the molecular consequences

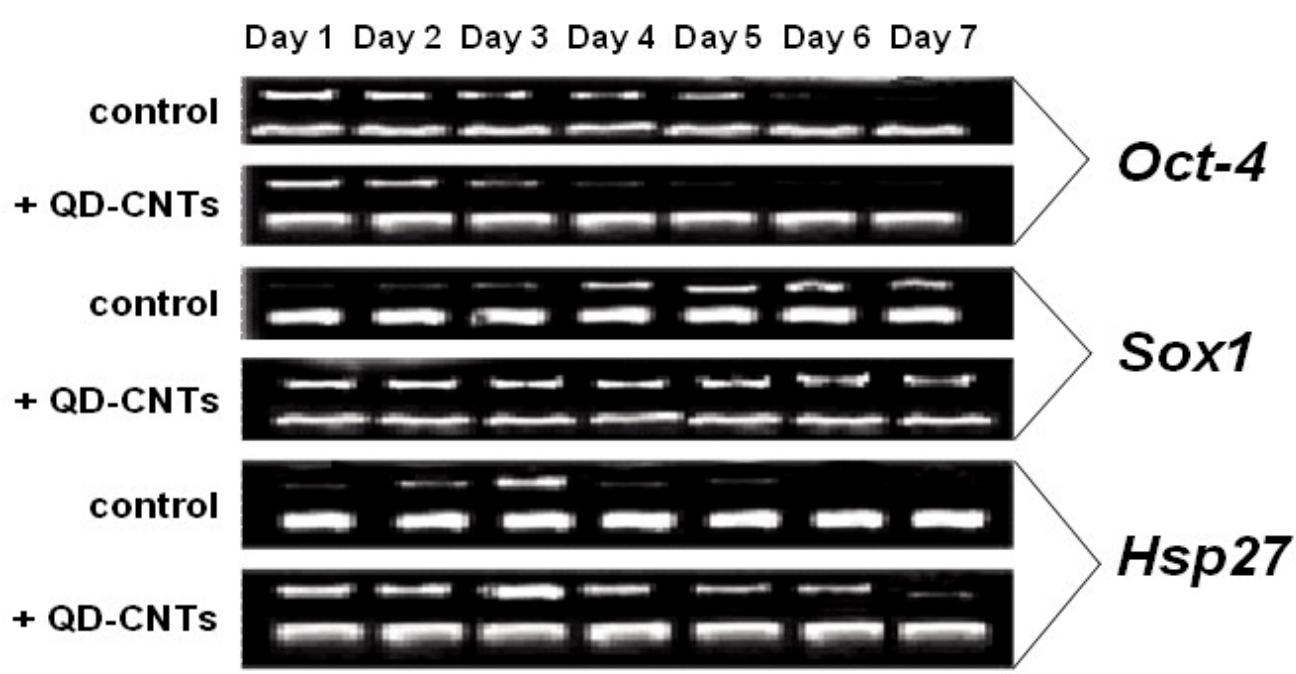

Figure 4 Effect of FMNTs on the differentiation of embryonic stem cells. Temporal transcription pattern of selected marker genes for differentiation of CCE ES cells was monitored for 7 days using RT-PCR. Cells were incubated in the presence and absence of $5 \mu \mathrm{g} \mathrm{mL}^{-1}$ of FMNTs and total RNA was isolated and processed as described in Methods. Oct- 4 is a gene highly expressed during the undifferentiated state of CCE ES cells, Sox 1 and Hsp27 are marker genes up-regulated during differentiation. $\beta$-Actin was used as internal control.

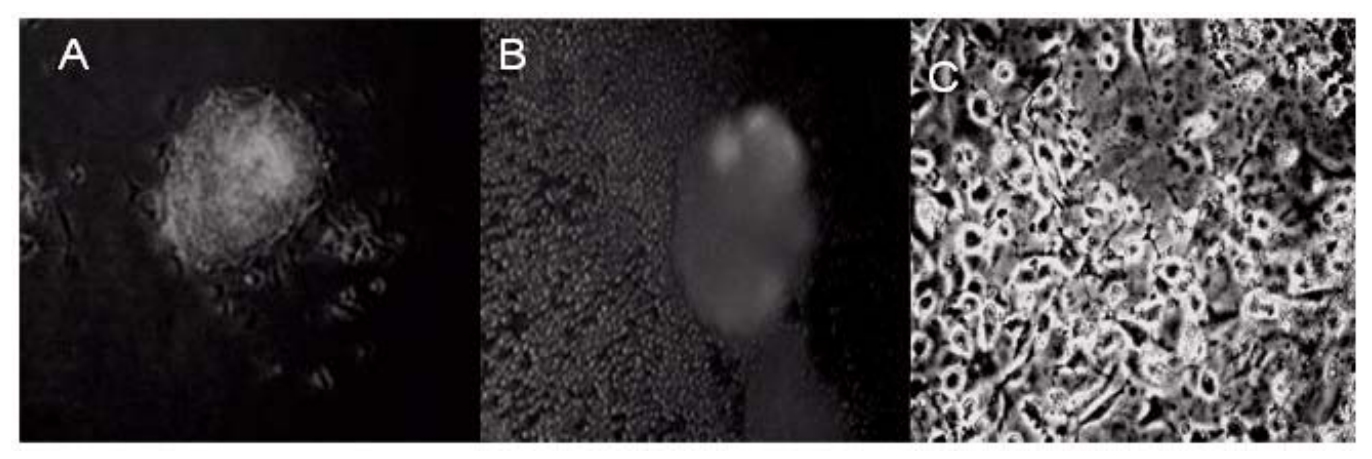

Figure 5 Active reactions of stem cells against FMNTs. (A) Stem cells treated with $5 \mu \mathrm{g} \mathrm{mL^{-1 }}$ FMNTs, the stem cells are attached to the surface of walls with normal growth, (B) and (C) ES cells are differentiated into nerve cells under the non-sera medium. 


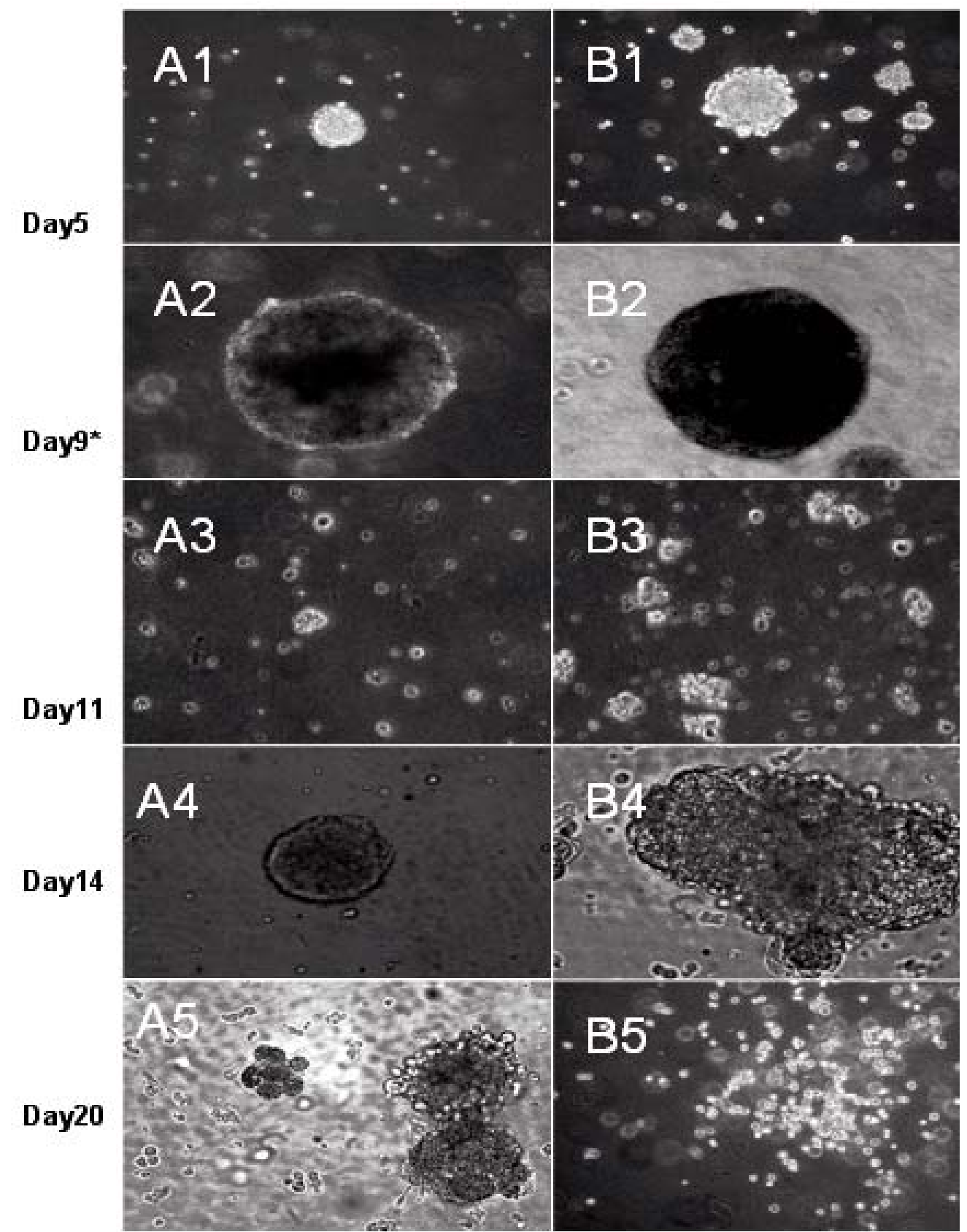

Figure 6 Morphological changes during hematopoietic differentiation of EBs from murine stem cells treated with $5 \mu \mu \mathrm{g} \mathrm{mL}{ }^{-1} \mathrm{FMNTs}_{\text {(right column) }}$ or without (left column). The EBs formed transferred for secondary differentiation in methylcellulose-containing culture media described in Methods.
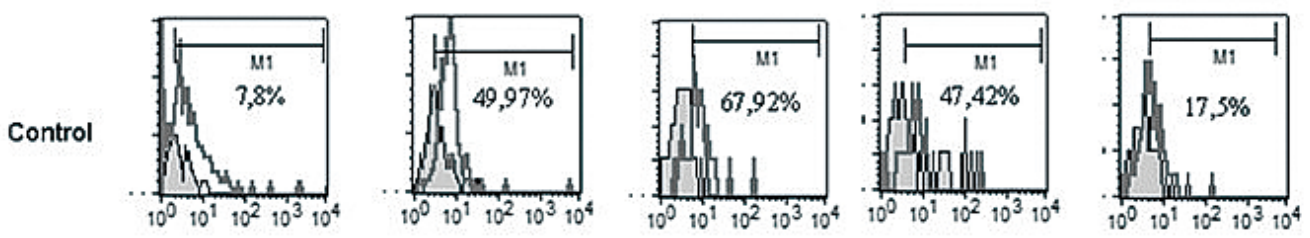

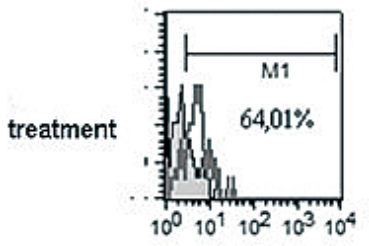

Day2

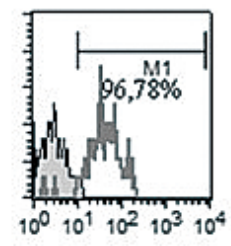

Day2.5

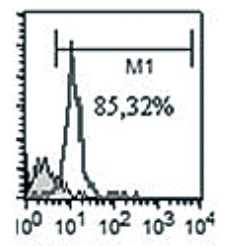

Day3

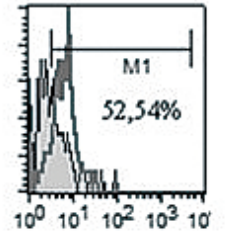

Day3.5

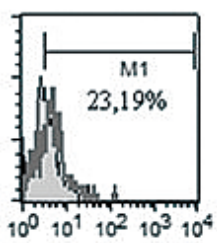

Day4

Figure 7 Expression of differentiation marker Flk-1 on CCE ES cells following incubation with (treatment group)or without (control group) $5 \mu \mathrm{g} \mathrm{mL}{ }^{-1}$ of FMNTs. Cell samples were collected between day 2-4 after treatment and processed for flow cell cytometry as described in Methods. 
associated with internalization of FMNTs in ES cells. Combined with advances in cell signaling pathways that regulate proliferation and differentiation of hematopoietic stem cells, future research efforts will delineate molecular events underlying dose-dependent regulation of proliferation and differentiation of ES cells by internalized FMNTs.

\section{Conclusion}

In summary, acrylic acid-coated, multiwalled carbon nanotubes with surface-conjugated QDs represent a unique nanostructured material that efficiently accumulates in mouse embryonic stem cells rendering them highly fluorescent. Low doses of internalized FMNTs enhance the differentiation of CCE ES cells, while exposure to high doses decreases cell proliferation rate and viability. These results imply that FMNTs may serve as a novel platform facilitating non-invasive in vivo monitoring of stem cells. Simultaneously, FMNTs are effective in regulating ES cell differentiation and offer significant cargo capacity for intracellular delivery of biomolecules, including DNA, RNA, peptides, or proteins, required to control stem cell differentiation. Further studies will focus on application and potential effects of FMNTs in in vivo imaging, tracking and distribution of ES cells in murine body.

\section{Acknowledgments}

This work was supported by a grant from Strategic Fund for Establishing the International HQs of Universities in Waseda University, Chinese 973 Project (2010CB933901), 863 Key Project (2007AA022004), New Century Excellent Talent of Ministry of Education of China(NCET-08-0350), Special Infection Diseases Key Project of China (2009ZX10004-311), Shanghai Science and Technology Fund (10XD1406100 and 1052nm04100 ). Donglu Shi, Giovanni M. Pauletti, Hoon Sung Cho, and Chris Huth are grateful to the support from The Institute for Nanoscale Science and Technology, University of Cincinnati.

\section{References}

1. Evans M J, Kaufman M H. Establishment in culture of pluripotential cells from mouse embryos. Nature. 1981; 292:154-156. doi:10.1038/292154a0

2. Park I H, Lerou P H, Zhao R, Huo H, Daley G Q. Generation of human-induced pluripotent stem cells. Nat. Protoc. 2008; 3:11801186 . doi:10.1038/nprot.2008.92

3. Nakatsuji N, Nakajima F, Tokunaga K. HLA-haplotype banking and iPS cells. Nat. Biotechnol. 2008;26: 739-740 . doi:10. 1038/nbt0708-739

4. Wood S A, Allen N D, Rossant J, Auerbach A, Nagy A. Noninjection methods for the production of embryonic stem cellcembryo chimeras. Nature.1993;365: 87-89. dio:10.1038/3650 $25 \mathrm{a} 0$

5. López M N. Ethical principles in research related to regenerative therapy. Cuad Bioet. 2008;19,:195-210 6. Larocca D, Wittee A, Johnson W, Pierce G F, Baird A. Targeting bacteriophage to mammalian cell surface receptors for gene delivery. Hum. Gene Ther. 1988;9:2393-2399

7. Gao H, Kong Y, Cui D, Ozkan C S. Spontaneous insertion of DNA oligonucleotides into carbon nnaotubes. Nano Lett. 2003; 3: 471-473 . doi: 10.1021/n1025967a

8. Cui D, Ozkan C S, Ravindran S, Kong Y, Gao H. Encapsluation of Pt-labled DNA molecules inside carbon nnaotubes. Mech. Chem. Biosyst. 2004;1:113-121.
9. Cui D. Advance and prospect of biomolecules functionalized carbon nanotubes. J. Nanosci. Nanotechnol.2007; 7: 1298-314 .doi:10.1166/ jnn.2007.654

10.Cui D, Tian F, Coyer CR, et al. Effects of as-myc conjugated single-walled carbon nanotubes on HL-60 cells. J. Nanosci. Nanotechnol. 2007; 7:1639-1646. doi:10.1166/jnn.2007.348

11.Kam N W S, O’Connell M, Wisdom J A, Dai H. Carbon nanotubes as multifunctional biological transporters and near-infrared agents for selective cancer cell destruction. Proc. Natl. Acad. Sci. U. S. A 2005;102:11600-11605. doi:10.1073/ pnas.0502680102

12.Kam SW, Liu Z, Dai H. Carbon nanotubes as intracellular transporters for proteins and DNA: an investigation of the uptake mechanism and pathway. Angew. Chem., Int. Ed. 2006; 45:577-581 . doi:10.1002/anie.200503389

13.Guo Y, Shi D, Cho H, Dong Z Y, Kulkarni A, Pauletti G M,Wang W, Lian J, Liu W, Ren L, Zhang Q, Liu GK, Huth C, Wang L M, Ewing R C. In vivo imaging and drug storage by quantum-dotconjugated carbon nanotubes. Adv. Funct. Mater.2008;18:1-9. doi:10.1002/adfm.200800406

14.Cui D, Zhang H, Wang Z, Toru A, Tetsuya O. Effects of dendrimer-functionalized multi-walled carbon nanotubes on murine embryonic stem cells. ECS Trans. 2008;13:111116.doi:10.1149/1.2998536

15.Wang Z, Ruan J, Cui D. Advances and prospect of nanotechnology in stem cells. Nanoscale Res. Lett. 2009;4:593-605. doi:10.1007/s11671$009-9292-z$

16.Turksen K (Ed.) Embryonic stem cells Methods and Protocols. Human Press, 2002.

17.Hattori N, Nishino K, Ko K, Hattori N, Ohgane J, Tanaka S, Shiota K. Epigenetic Control of Mouse Oct-4 Gene Expression in Embryonic Stem Cells and Trophoblast Stem Cells. J. Biol. Chem. 2004;279:17063-17069. doi:10.1074/jbc.M309002200

18.Park C, Afrikanova I Chung Y S, et al., A hierarchical order of factors in the generation of FLK1- and SCL-expressing hematopoietic and endothelial progenitors from embryonic stem cells. Development. 2004;131:2749-2762. doi:10.1242/ dev.01130

19.Rao R R, Stice S L. Gene expression profiling of embryonic stem cells leads to greater understanding of pluripotency and early developmental events. Biol. Reprod. 2004;71: 1772-1778. doi:10.1095/biolreprod.104.030395

20.Pantarotto D, Briand J P, Prato M, Bianco A. Translocation of bioactive peptides across cell membrane by carbon nanotubes. Chem. Commun. 2004;7:16-17. doi:10.1039/b311254c

21.Pantarotto D, et al. Functionalized carbon nanotubes for plasmid DNA gene delivery. Angew. Chem., Int. Ed. 2004;43:5242 -5246. doi:10.1002/anie.200460437

22.Gallagher JT, Morris AJ, Dexter TM. Developmentally-related changes in surface membrane glycopeptides of murine haemopoietic cells. Biochem. J. 1987;242:857-865.

23.Ji J,Ruan J ,Cui D ,Advance of nanotechnology in the stem cells research and development. Nano Biomed.Eng.2010;2:67-90

24. Kostarelos K Lacerda L, Pastorin G, Wu W, Wickowski S, Luanay J, Godefroy S, et al. Cellualr uptake of functionalized carbon nanotubes is independent of functional group and cell type. Nat. Nanotechnol. 2007;2:108-113. doi:10.1038/ nnano. 2006.209

25.Lopez C F, Nielsen S O, Moore P B, Klein M. Understanding nature's design for a nanosyringe. Proc. Natl. Acad. Sci. U. S. A. 2004; 101:4431-4434. doi:10.1073/pnas.0400352101

26.Cui D, Tian F, Ozkan C S, Wang M, Gao H. Effects of single wall carbon nanotubes on HEK293 cells. Toxicol. Lett. 2005; 155 : 73-85. doi:10.1016/j.toxlet.2004.08.015

27.Robert F. Nanomaterials show signs of toxicity. Science. 2003; 300:243. doi:10.1126/science.300.5617.243a

28.Spike B T, Macleod K F. Effects of hypoxia on heterotypic macrophage interactions. Cell Cycle 2007;6:2620-2624. doi:10. 4161/cc.6.21.4879

29. Yuan H, Hu S Huang P, Song H, Wang K, Ruan J, et al.Singlewalled carbon nnaotubes exhibit dual-phase regulation to exposed Arabidopsis mesophyll cells. Nanoscale Res. Lett. 2010; doi:10.1007/ s11671-010-9799-3.

30.Tian FR, Cui D, Schwarz H Estrada G G, Kobayashi,H. Cytotoxicity of single-wall carbon nanotubes on human fibroblasts.Toxicol. In Vitro 2006;20:1202-1212. doi:10.1016/j.tiv. 
2006.03.008

31.Pan B, Cui D, He R, Gao F, Zhang Y. Covalent attachment of quantum

dot on carbon nanotubes. Chem. Phys. Lett. 2006;417:419-424. doi: $10.1016 /$ j.cplett.2005.10.044

32.Pan B, Cui D, Xu P, Chen H, Liu F T, Li Q, et al. Design of dendrimer modified carbon nanotubes for gene delivery. Chin. J. Cancer Res. 2007;19:1-6. doi:10.1007/s11670-007-0001-0
Received 10 November, 2010; accepted 6 December, 2010; published online 16 December, 2010.

Copyright:(c) 2010 D. Cui, et al. This is an open-access article distributed under the terms of the Creative Commons Attribution License, which permits unrestricted use, distribution, and reproduction in any medium, provided the original author and source are credited. 